\title{
Optimization of Carbon Nanotube Layer Formation on Plasma-Polymerized Thin Film for Enzyme Biosensor
}

\author{
Yasunori Matsui, Masahiro Yoshizawa, \\ Tatsuya Hoshino and Hitoshi Muguruma* \\ Department of Electronic Engineering, Shibaura Institute of Technology, \\ 3-7-5 Toyosu, Koto-ku, Tokyo 135-8548, Japan
}

(Received April 7, 2008; accepted September 5, 2008)

Key words: amperometric biosensor, glucose oxidase, plasma-polymerized film, carbon nanotube

An electrochemical biosensor based on a carbon nanotube (CNT) layer with glucose oxidase (GOx) enzyme sandwiched between 6-nm-thick acetonitrile plasmapolymerized films (PPFs) was fabricated. The lower PPF was deposited onto a sputtered gold electrode. The optimization of the casting formation of the CNT layer onto the lower PPF is addressed. As a result, the best candidate for the casting solution was a 1:1 mixture of phosphate buffer and ethanol, and the optimized CNT concentration was $7.5 \mathrm{mg} \mathrm{ml}^{-1}$. The optimized glucose biosensor characteristics exhibited ultrasensitivity (a sensitivity of $11 \mu \mathrm{A} \mathrm{mM}^{-1} \mathrm{~cm}^{-2}(4.9-19 \mathrm{mM}$ ), a detection limit of $6.2 \mu \mathrm{M}$ at $\mathrm{S} / \mathrm{N}=3,+0.8 \mathrm{~V}$ $\mathrm{vs} \mathrm{Ag} / \mathrm{AgCl}$ ), and a rapid response ( $<4 \mathrm{~s}$ to reach $95 \%$ of maximum response). This high performance is attributed to the excellent electrocatalytic activity and enhancement of electron transfer that CNTs provide, and because the PPF and/or plasma process for CNTs are an enzyme-friendly platform.

\section{Introduction}

Carbon nanotubes (CNTs) ${ }^{(1)}$ have been given much attention because of their unique properties. CNTs have interesting nanostructures that consist of hollow cylindrical graphene layers that display excellent electrical conductivity, high surface-area-to-volume ratio, high mechanical strength, and high chemical stability. Recently, amperometric enzyme biosensors using CNTs have been increasingly reported.(2-14) The typical structure of a CNT-based amperometric biosensor is a combination of biomolecules (e.g., enzymes) and CNTs in the vicinity of an electrode. However, one requirement is that the hydrophobic surface of the CNTs must be changed to a hydrophilic surface in order

*Corresponding author: e-mail: muguruma@sic.shibaura-it.ac.jp 
to be combined with enzymes when used in the aqueous phase. Some strategies have been reported to address this: the introduction of chemically active functional groups by the treatment of CNTs with sulfonic or nitric acid, which then enables subsequent modification. ${ }^{(2-4)}$ Another strategy is the dispersion of CNTs within a matrix such as Nafion, ${ }^{(5,6)}$ a redox hydrogel, ${ }^{(7,8)}$ or other polymers. ${ }^{(9-11)}$ However, these methods require that the enzymes and other biomolecules receive careful treatment in order to retain their tertiary structure.

Recently, a method where the CNTs are directly treated by plasma has been reported. ${ }^{(15-18)}$ The advantage of this modification is that functional groups such as amino and carboxyl groups can be easily introduced onto the side wall and/or edge of the CNTs, without the inclusion of impurities. Using a different approach, we have proposed an amperometric biosensor based on a plasma-polymerized thin film (PPF), in which the PPF is achieved by glow discharge or plasma in the vapor phase. ${ }^{(19-22)}$ For the PPF, acetonitrile, a monomer, is suitable for the interfacial design between the biological component (enzyme) and the electrode, because of the highly branched and crosslinked aliphatic hydrocarbon backbone chains that contain nitrogen atoms in the form of primary amine groups.

On this basis, a first attempt was made to combine PPF and/or plasma modification with a CNT-based amperometric biosensor application. Glucose oxidase (GOx) is the most common enzyme used as a biological component in glucose biosensors, which are used to assist diabetes mellitus patients to monitor their daily sugar level. ${ }^{(23,24)}$ The proposed method not only simplifies the configuration of the CNT-enzyme electrode, but also significantly enhances the electrochemical contact between the reaction center of the enzyme and the electrode via the CNTs. In this article, the optimization of the casting formation of a CNT layer onto the lower PPF is mainly addressed.

\section{Materials and Methods}

\subsection{Chemicals}

Distilled water, potassium dihydrogenphosphate, disodium hydrogenphosphate, $D$-glucose, ethanol, hydrogen peroxide, ammonia, and acetonitrile were purchased from Kanto Chemical Inc. (Tokyo, Japan). GOx obtained from Aspergillus niger (EC 1.1.3.4,

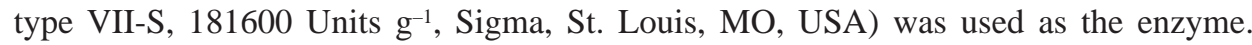
Single-walled CNTs were purchased from Wako Chemical Inc. (Osaka, Japan). All the reagents used in this investigation were used without further purification.

\subsection{Device fabrication}

The device was formed on a 0.15 -mm-thick glass substrate with planar dimensions of approximately $50 \times 50 \mathrm{~mm}^{2}$. All the metal layers were sputter-deposited and patterned by a masking process. The glass slides used to make the thin film electrodes were boiled in a hydrogen peroxide/ammonia/water solution (approximately 1:1:8 by volume) for $1 \mathrm{~h}$, and then rinsed with water and acetone. Au thin films were deposited using sputtering apparatus (VEP-1000, Ulvac Inc., Tokyo, Japan). A 40-nm-thick Cr intermediate layer was used to promote the adhesion of the Au layer. The dimensions of the opening for the 
working electrode were $5 \times 5 \mathrm{~mm}^{2}$.

A plasma generator (VEP-1000, Ulvac) was used to deposit a 6-nm-thick acetonitrilePPF (AN-PPF) layer (first/lower PPF) onto the sputtered Au electrode at $150 \mathrm{~W}$ and under a pressure of $0.6 \mathrm{~Pa}$ for a deposition time of $60 \mathrm{~s}$. The CNTs were dispersed in a 1:1 mixed solution of ethanol and phosphate buffer solution $(20 \mathrm{mM}, \mathrm{pH} 7.4)$ in which the optimized CNT concentration was $0.75 \mathrm{mg} \mathrm{ml}^{-1}$. The CNT suspension was deposited dropwise onto the PPF surface and then dried in a vacuum oven. Subsequently, the CNT-adsorbed surface was treated with nitrogen plasma under the following conditions: power, $100 \mathrm{~W}$ (optimized); flow rate, $15 \mathrm{ml} \mathrm{min}^{-1}$; pressure, $3 \mathrm{~Pa}$; exposure time, $60 \mathrm{~s}$. The enzyme was then added dropwise to an aliquot of $\mathrm{GO} x\left(10 \mathrm{mg} \mathrm{ml}^{-1}\right)$ in the phosphate buffer onto the film. One hour later, the device was washed with water. Finally, the enzyme-adsorbed surface was coated with a second AN-PPF layer (6 nm thickness) using the same deposition conditions as those for the first PPF. The devices were stored in a refrigerator at $4^{\circ} \mathrm{C}$ until use.

\subsection{Measurements}

Cyclic voltammetry (CV) was performed using an electrochemical analyzer (Model 701A, ALS Instruments, West Lafayette, IN, USA), with a three-electrode configuration. A reference electrode $(\mathrm{Ag} / \mathrm{AgCl}, \mathrm{RE}-1 \mathrm{C})$ and a counter electrode (platinum wire) were purchased from Bioanalytical Systems Inc (West Lafayette, IN, USA). Electrochemical measurements were carried out in a $10 \mathrm{ml}$ vessel at ambient temperature $\left(20 \pm 1^{\circ} \mathrm{C}\right)$. A phosphate buffer (20 mM, pH 7.4) was used as the supporting electrolyte. The measurement was carried out at least four times.

\section{Results and Discussion}

\subsection{Optimization of CNT layer formation}

The fabricated amperometric biosensor based on CNTs has a unique sandwich-like structure; the basic structure is represented as $\mathrm{PPF} / \mathrm{GO} / \mathrm{CNT} / \mathrm{PPF} / \mathrm{Au}$. The preparation scheme is shown in Fig. 1. CNTs are chemically inert and insoluble in most solvents; therefore, the cast CNT layer was formed by temporal dispersion in solution.

The CV response of the PPF/GOx/PPF/Au biosensor with a CNT layer cast using a 1:1 mixture of buffer and ethanol was higher than that of CNT layers cast using only buffer or only ethanol, as shown in Fig. 2. This confirms that the 1:1 buffer/ethanol mixture provides a more stable CNT suspension, as shown by the photograph of vial suspensions in Fig. 2. However, this suspension is less stable than that obtained by other processes using a binder such as Nafion, polypyrrole, and surfactants. ${ }^{(6-10,14)}$ Therefore, it is probable that the CNT layer is mechanically and electrically loose (probably due to slack packing). Combined with the subsequent plasma treatment, a high sensor response was obtained (Fig. 2(c)). This method for the formation and modification of a CNT layer is a very simple and clean process.

Optimization of the CNT concentration in the suspension solution for casting was carried out. Figure 3 shows CVs obtained in the presence and absence of glucose as a function of the CNT concentration. Comparing Figs. 3(a) and 3(b), it can be seen that 
(a)

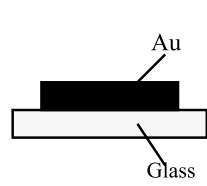

(d) $\mathrm{N}_{2}$ plasma

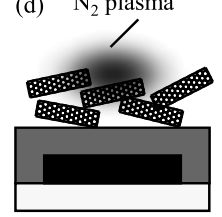

(b)

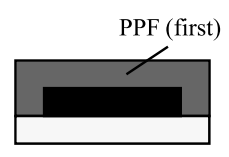

(e)

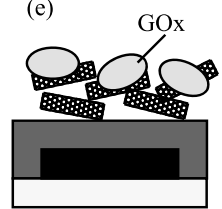

(c)

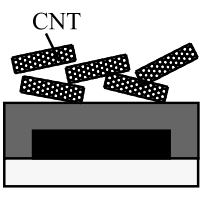

(f) PPF (second)

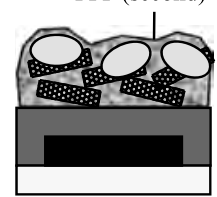

Fig. 1. Schematic representation of the fabrication of an amperometric biosensor based on CNTs and PPF layers. (a) Au electrodes are sputtered onto a glass substrate through a metal mask. (b) A 6-nm-thick acetonitrile plasma-polymerized film (first AN-PPF) was deposited. (c) Solution casting is used to form the CNT layer. (d) Nitrogen plasma treatment of the CNT layer. (e) Solution casting of the enzyme layer onto the CNT layer. (f) Immobilized GOx is coated by a second ANPPF.
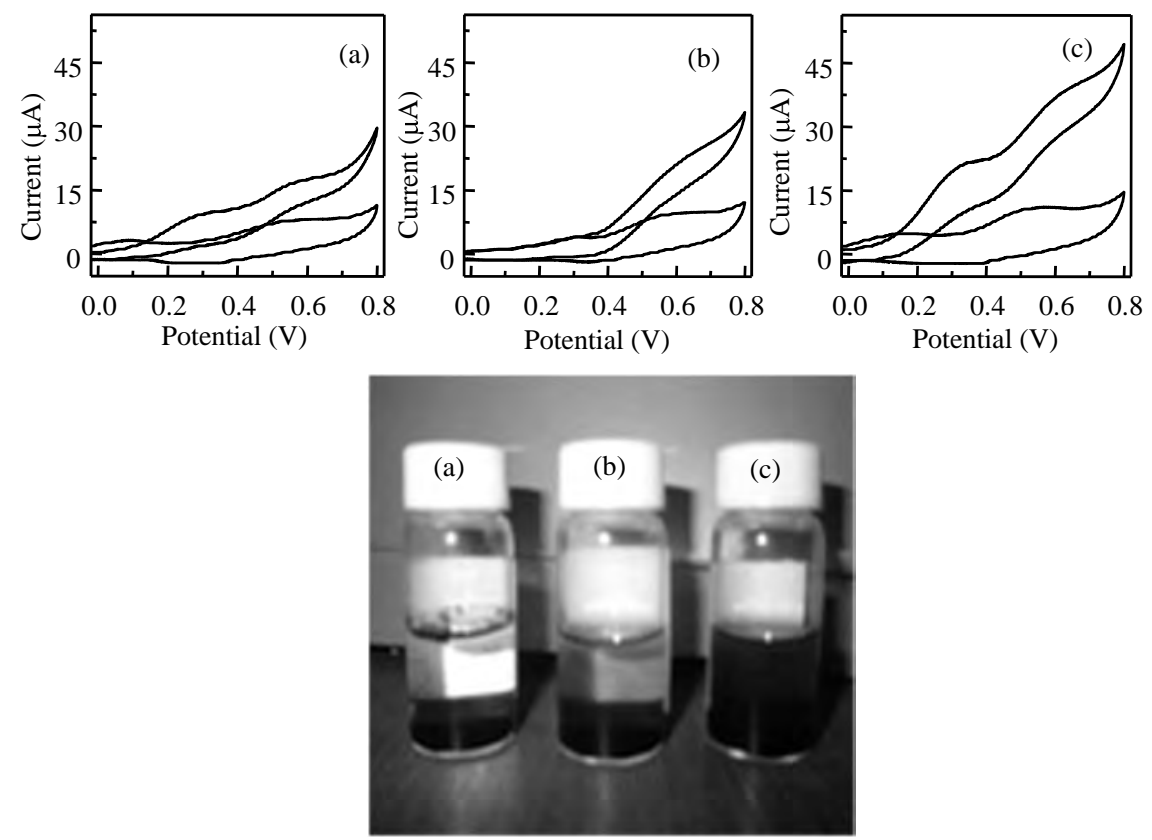

Fig. 2. CV response of the biosensor in the presence or absence of glucose. Sweep rate: $50 \mathrm{mV} \mathrm{s}^{-1}$; glucose concentration: $48 \mathrm{mM}$; pH 7.4; 20 mM phosphate buffer solution. CNTs were dispersed in (a) buffer solution, (b) ethanol, and (c) 1:1 mixture of buffer solution and ethanol. Photograph: Vials of CNT suspensions after $4 \mathrm{~h}$. 

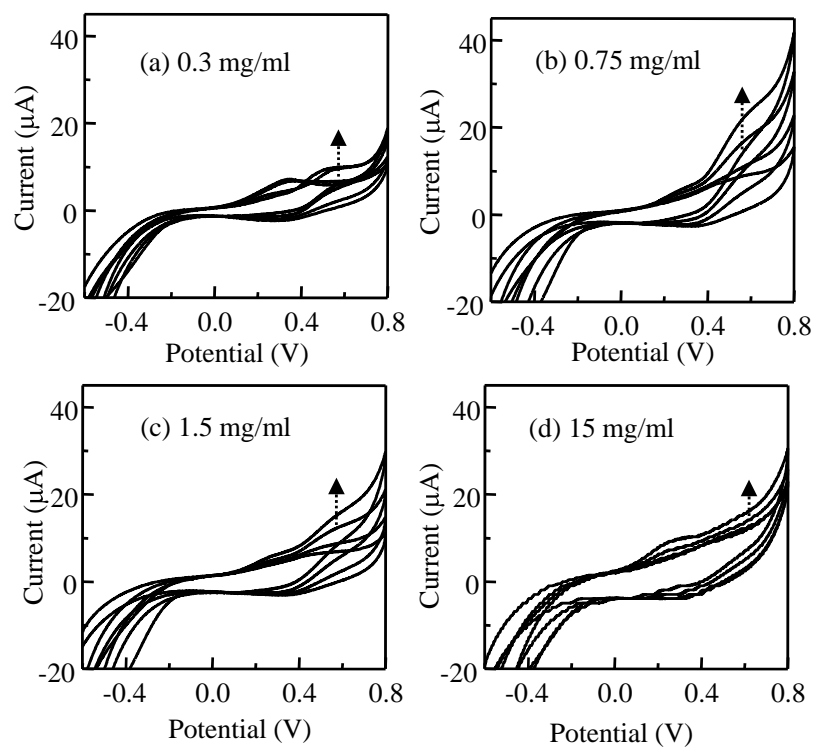

Fig. 3. Cyclic voltammograms of the fabricated amperometric glucose sensor using GOx, CNTs, and PPF (PPF/GOx/CNT/PPF/Au) as a function of the CNT concentration used for casting the CNT layer. CNT concentrations: (a) 0.3 , (b) 0.75 , (c) 1.5 , and (d) $15 \mathrm{mg} \mathrm{mL}^{-1}$. Arrow directions indicate the increase in current upon adding glucose with concentrations of $0,2.5,14$, and $48 \mathrm{mM}$. Conditions: $20 \mathrm{mM}$ phosphate buffer; $\mathrm{pH}=7.4 ; 20^{\circ} \mathrm{C}$; scan rate, $50 \mathrm{mV} \mathrm{s}^{-1}$; electrode area, $25 \mathrm{~mm}^{2}$.

the current obtained by adding glucose to the device with a CNT concentration of 0.75 $\mathrm{mg} \mathrm{ml}^{-1}$ was larger than that with a concentration of $0.3 \mathrm{mg} \mathrm{ml}^{-1}$. For the $\mathrm{CV}$ with the largest CNT concentration of $15 \mathrm{mg} \mathrm{ml}^{-1}$ (Fig. 3(d)), both the oxidation and background currents increased. The CNTs act as the catalyst or enable direct electron transfer via the CNTs (discussed next section). From these mechanisms, in spite of the higher concentration CNTs, the output current at the higher CNT concentration of $15 \mathrm{mg} / \mathrm{ml}$ was less than that at a concentration of $0.75 \mathrm{mg} \mathrm{ml}^{-1}$. This is because the number of CNTs is so large compared with that of the enzyme GOx that the generation of hydrogen peroxide and electrons due to the enzymatic reaction with glucose was reduced. This shows that in the design of the enzyme-CNT electrode it is necessary to consider the balance between the amounts of enzyme and CNTs. Therefore, the optimized concentration of CNTs was determined as $0.75 \mathrm{mg} \mathrm{ml}^{-1}$, due to the largest increment in current with glucose addition.

The PPF acts as the interface between the Au electrode and the GOx-CNT complex. A densely packed array of GOx molecules can be formed on the hydrophilic and positively charged surface of AN-PPF. The immobilized GOx molecules at the surface are in the form of a compact ellipsoid with approximate dimensions of $12.2 \times 8.3 \mathrm{~nm}^{2}$ (measured by AFM). ${ }^{(21,22)}$ Therefore, the redox center exists at a smaller pocket in the 
larger $(10 \mathrm{~nm})$ three-dimensional structure of GOx. The dimension of a single-walled CNT (1.2-2 nm) is smaller than that of GOx; therefore, access to the reaction center is possible. As a result, the effective electron contact with flavin adenine dinucleotide (FAD) is obtained.

Two mechanisms can be considered for the large current response. One is the catalytic activity of the $\mathrm{CNTs}^{(9,12,14)}$ toward hydrogen peroxide generated by the enzymatic reaction. $\mathrm{GO} x$ specifically catalyzes the oxidation of glucose as follows:

$$
\beta \text {-D-glucose }+\mathrm{O}_{2} \stackrel{\text { GOx }}{\longrightarrow} D \text {-gluconic acid }+\mathrm{H}_{2} \mathrm{O}_{2}
$$

and the CNT catalyzes the reaction of hydrogen peroxide as follows:

$$
\mathrm{H}_{2} \mathrm{O}_{2} \rightarrow 2 \mathrm{H}^{+}+\mathrm{O}_{2}+2 e^{-} \text {. }
$$

The Au electrode receives the electron, and as a result, the current increases. The other mechanism is the direct electron transfer via the CNTs, and a possible mechanism is

$$
\begin{gathered}
\beta \text {-D-glucose }+\mathrm{GO} x(\mathrm{FAD}) \rightarrow \delta \text {-gluconolactone }+\mathrm{GO} x\left(\mathrm{FADH}_{2}\right) \\
\mathrm{GOx}\left(\mathrm{FADH}_{2}\right)+2 \mathrm{M}_{\mathrm{ox}} \rightarrow \mathrm{GOx}(\mathrm{FAD})+2 \mathrm{M}_{\mathrm{red}}+2 \mathrm{H}^{+} \\
2 \mathrm{M}_{\mathrm{red}} \rightarrow 2 \mathrm{M}_{\mathrm{ox}}+2 e^{-},
\end{gathered}
$$

where FAD is located in the vicinity of the reaction center of $\mathrm{GO} x$, and $\mathrm{M}$ represents an electron transfer mediator.

\subsection{Sensor performance}

The previous sections have presented the optimization of the sensor fabrication process based on CNTs and PPF. In this section, the performance of the optimized biosensor device is demonstrated. Figure 4 shows the steady-state amperometric response at $+0.8 \mathrm{~V}$ vs $\mathrm{Ag} / \mathrm{AgCl}$. The sequential increase in current is observed upon glucose addition, and the sensor response covers a wide range of glucose concentrations $(0.025-27 \mathrm{mM})$. A remarkable characteristic is the small background current $(0.68 \pm 0.04 \mu \mathrm{A})$ compared with the glucose response, indicating that there is no need to calibrate the baseline for the glucose measurement. This is because the nano-sandwich structure and the permiselective coating ${ }^{(20)}$ of the first PPF layer on the Au electrode provide effective electrochemical communication. The detection limit ( $\mathrm{S} / \mathrm{N}$ ratio: 3 ) is $6 \mu \mathrm{M}$. The nanometersized sandwich-like configuration provides a suitable distance for electrochemical communication between the electrode and the reaction center of the enzyme. As a result, a short response time ( $<4 \mathrm{~s}, 95 \%$ to maximum response) was obtained.

Figure 5 shows the current vs glucose concentration based on the data from Fig. 4. The biosensor has a stability for $4.1 \%$ of the relative standard deviation (RSD) during four individual detections. The characteristics of this device display good linearity ( $r=$ 


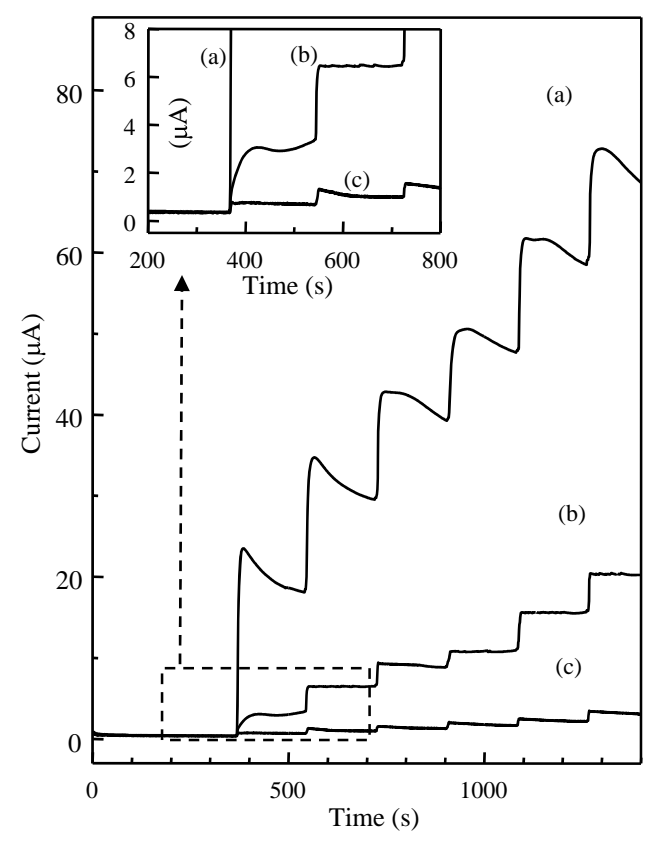

Fig. 4. Time-dependent response to glucose addition (a) 2.5, 4.9, 7.3, 9.6, 14, 19, and $27 \mathrm{mM}$, (b) $0.25,0.49,0.73,0.96,1.4,1.9$, and $2.7 \mathrm{mM}$, and (c) $0.025,0.049,0.073,0.096,0.14,0.19$, and $0.27 \mathrm{mM}$. Polarization potential: $0.8 \mathrm{~V}$ vs Ag/AgCl. Response time: $4 \mathrm{~s}$ (95\% to maximum level). Detection limit: $6.2 \mu \mathrm{M}(S / N=3)$.

0.993) for the sugar levels usually encountered in diabetes patients (4.9-19 mM), and the sensitivity is $3.3 \mu \mathrm{A} \mathrm{mM} \mathrm{mm}^{-1} \mathrm{~cm}^{-2}$. Deviation from linearity is observed at higher (> $20 \mathrm{mM}$ ) glucose concentrations, representing a typical characteristic of the Michaelis-Menten model. The apparent Michaelis-Menten activity $\left(K_{\mathrm{M}}\right.$ app $)$ of the immobilized enzyme was calculated using the Lineweaver-Burk plot shown in the inset of Fig. 5. According to the plot, the $K_{\mathrm{M}}$ app is calculated to be $17 \mathrm{mM}$. This value is similar to those of other CNT-based biosensors ${ }^{(25,26)}$ and is smaller than that for GOx in solution (33 mM). ${ }^{(26)}$ The obtained maximum current density of $0.44 \mathrm{~mA} \mathrm{~cm}^{-2}$ is comparable to those of other CNT-based biosensors. ${ }^{7,25,27,28)}$ However, it should be emphasized that the proposed drychemical-based biosensor is a simple, robust, reproducible, and has a reliable fabrication method, i.e., there are no requirements for cumbersome modification steps for the "wiring" of the enzyme ${ }^{(2)}$ and the self-assembled reconstruction of the apo-enzyme. ${ }^{(28)}$

The GOx enzyme was adsorbed onto the layer of CNTs, and AN-PPF was formed on the enzyme-CNT layer. The second coating of AN-PPF prevents leaching and contamination of the GOx and CNTs. The other advantage of the second AN-PPF coating is demonstrated in Fig. 6, which shows the operational stability under continuous polarization. For the device without the AN-PPF coating, the current decreased to $25 \%$ of the initial level after $24 \mathrm{~h}$, owing to the leaching of the physisorbed GOx and CNTs 


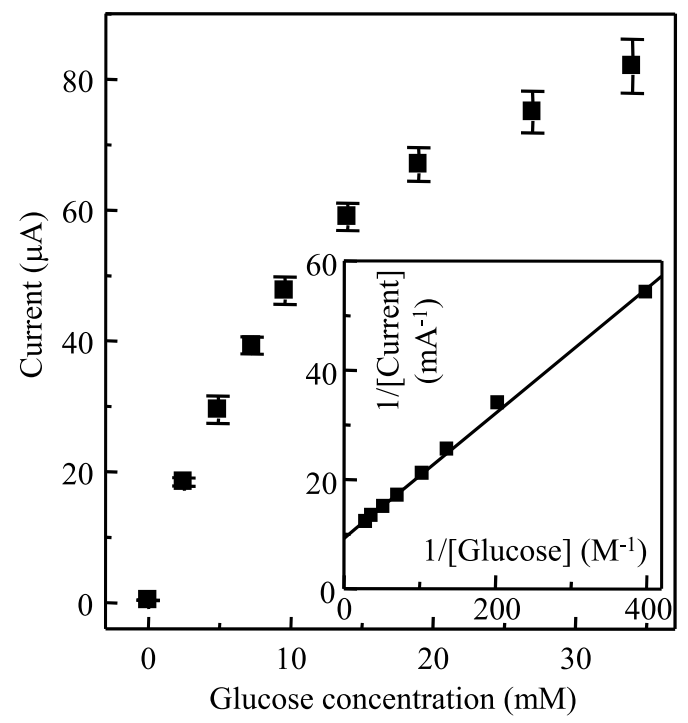

Fig. 5. Calibration plot for the glucose response using the data from Fig. 4. There is a linear relationship with a high correlation in the low-glucose-concentration range (4.9-19 mM) and a sensitivity of $11 \mu \mathrm{A} \mathrm{mM}^{-1} \mathrm{~cm}^{-2}(r=0.983)$. Each point represents the average of measurement and the vertical bars designate the relative standard deviation $(n=4)$. Inset: Lineweaver-Burk plot. $I_{\max }$, $0.44 \mathrm{~mA} \mathrm{~cm}^{-2} ; K_{\mathrm{M}}^{\mathrm{app}}, 12 \mathrm{mM}$.

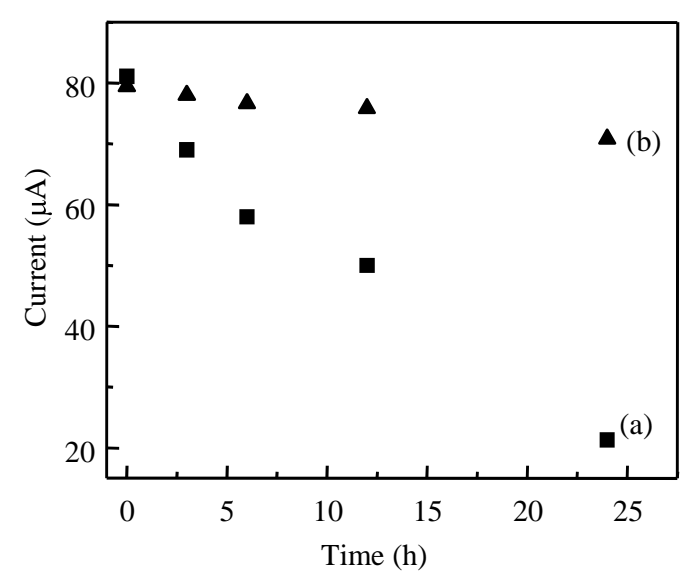

Fig. 6. Operational stability of the biosensor under continuous operation. The polarization potential was $+0.8 \mathrm{~V}$ vs $\mathrm{Ag} / \mathrm{AgCl}$ at a glucose concentration of $48 \mathrm{mM}$, with an electrolyte of $\mathrm{pH} 7.4$; $20 \mathrm{mM}$ phosphate buffer solution. The working electrodes are (a) GOx/CNT/PPF/Au (no second coating) and (b) PPF/GOx/CNT/PPF/Au. 
onto the first PPF. The second AN-PPF coating prevents this leaching, and retained more than $90 \%$ of the initial response after $24 \mathrm{~h}$. Despite the direct treatment of the GOx enzyme with highly energetic plasma species, the GOx immobilized on the surface of the CNTs retained its activity. This suggests that the protein can be combined with a dry process for device fabrication.

\section{Conclusions}

A new simple and reliable method for the fabrication of a CNT-based amperometric biosensor was demonstrated. CNTs and GOx enzyme were sandwiched between 6-nm-thick AN-PPF layers on a sputtered gold electrode. Optimization of the casting formation of a CNT layer onto the lower AN-PPF layer was focused on. An organic plasma polymer coating method and a semiconductor-technology-compatible layerby-layer process provided a well-defined nanocomposite of the enzyme, CNTs, and PPFs. This highly efficient electron transfer system was able to detect a relevant bioelectrochemical signal equal to $0.44 \mathrm{~mA} \mathrm{~cm}^{-2}$. This also suggests that the PPF and/ or plasma process is a suitable interface design for electrochemical communication from the reaction center of GOx to an electrode via CNTs. The method presented here can be easily extended to other biosensor devices using other enzymes and proteins. As a simple dry process intended for mass production, this might be of benefit to the development of microscale and/or arrayed sensors.

\section{References}

1 S. Iijima: Nature 354 (1991) 56.

2 J. J. Gooding, R. Wibowo, J. Liu, W. Yang, D. Losic, S. Orbons, F. J. Mearns, J. G. Shapter and D. B. Hibbert: J. Am. Chem. Soc. 125 (2003) 9006.

3 B. R. Azamian, J. J. Davis, K. S. Coleman, C. B. Bagshaw and M. L. H. Green: J. Am. Chem. Soc. 124 (2002) 12664.

4 G. Liu and Y. Lin: Electrochem. Commun. 8 (2006) 251.

5 Y.-C. Tsai, S.-C. Li and J.-M. Chen: Langmuir 21 (2005) 3653.

6 S. Hrapovic, Y. Liu, K. B. Male and J. H. T. Luong: Anal. Chem. 76 (2004) 1083.

7 P. P. Joshi, S. A. Merchant, Y. Wang and D. W. Schmidtke: Anal. Chem. 77 (2005) 3183.

8 Y. Wang, P. P. Joshi, K. L. Hobbs, M. B. Johnson, and D. W. Schmidtke: Langmuir 22 (2006) 9776.

9 J. Wang and M. Musameh: Anal. Chem. 75 (2003) 2075.

10 V. G. Gavalas, S. A. Law, J. C. Ball, R. Andrews and L. G. Bachas: Anal. Biochem. 329 (2004) 247.

11 X. B. Yan, X. J. Chen, B. K. Tay and K. A. Khor: Electrochem. Commun. 9 (2007) 1269.

12 A. Salimi, R. G. Compton and R. Hallaj: Anal. Biochem. 333 (2004) 49.

13 H. Muguruma, Y. Shibayama and Y. Matsui: Jpn. J. Appl. Phys. 46 (2007) 6078.

14 A. Merkoçi, M. Pumera, X. Llopis, B. Pérez, M. Valle and S. Alegret: TrAC-Trend. Anal. Chem. 24 (2005) 826. 
15 B. Khare, P. Wilhite, B. Tran, E. Teixeira, K. Fresquez, D. N. Mvondo, C. Bauschlicher, Jr. and M. Meyyappam: J. Phys. Chem. B 109 (2005) 23466.

16 B. Khare, P. Wilhite, R. C. Quinn, B. Chen, R. H. Schingler, B. Tran, H. Imanaka, C. R. So, C. Bauschlicher, Jr. and M. Meyyappam: J. Phys. Chem. B 108 (2004) 8166.

17 B. Khare, M. Meyyappam, A. M. Cassell, C. V. Nguyen and J. Han: Nano Lett. 2 (2002) 73.

18 N. O. V. Plank, G. A. Forrest, R. Cheung and A. J. Alexander: J. Phys. Chem. B 109 (2005) 22096.

19 H. Muguruma: TrAC-Trend. Anal. Chem. 26 (2007) 433.

20 H. Muguruma, A. Hiratsuka and I. Karube: Anal. Chem. 72 (2000) 2671.

21 H. Muguruma, Y. Kase and H. Uehara: Anal. Chem. 77 (2005) 6557.

22 H. Muguruma and Y. Kase: Biosens. Bioelectron. 22 (2006) 737.

23 E. Wilkins and P. Atanasov: Med. Eng. Phys. 18 (1996) 273.

24 M. Ishikawa, D. W. Schmidtke, P. Raskin and C. A. P. Quinn: J. Diab. Comp. 12 (1998) 295.

25 H. Tang, J. Chen, S. Yao, L. Nie, G. Deng and Y. Kuang: Anal. Biochem. 331 (2004) 89.

26 Y. Liu, M. Wang, F. Zhao, Z. Xu and S. Dong: Biosens. Bioelectron. 21 (2005) 984.

27 D. Pan, J. Chen, S. Yao, W. Tao and L. Nie: Anal. Sci. 21 (2005) 367.

28 F. Patolsky, Y. Weizmann and I. Willner: Angew. Chem. Int. Ed. 43 (2004) 2113. 